\title{
Twelve-Month Prevalence of Psychiatric Morbidity in Cancer Patients in a Nigerian Oncology Centre
}

Victor Lasebikan ( $\nabla$ victorlash@yahoo.com )

College of Medicine, University of Ibadan

Shina Fakunle

University College Hospital Ibadan

Tiwatayo Lasebikan

Federal Neuropsychiatric Hospital, Yaba

Morufat Abosede Alabi

University of Ibadan College of Medicine

Adeniyi Adenipekun

Department of Radiation Onology, College of Medicine, University of Ibadan

Research article

Keywords: Cancer, Psychological Distress, Psychosocial Distress, Psychiatric-Morbidity, Consultation-Liaison Psychiatric Service

Posted Date: April 4th, 2020

DOI: https://doi.org/10.21203/rs.3.rs-19104/v1

License: (c) (1) This work is licensed under a Creative Commons Attribution 4.0 International License. Read Full License 


\section{Abstract}

Background Cancer is a leading cause of mortality worldwide and is associated with a wide range of psychiatric morbidity.

Methods In this descriptive study, 130 patients with different types of cancer were interviewed. Information on sociodemographic characteristics, medical comorbidity, stage of cancer, duration of treatment was obtained. Psychological distress was assessed using the GHQ-12, and psychosocial distress with the Distress Thermometer (DT). The MINI was used to establish the presence or absence of any psychiatric diagnosis, including any substance use disorder. Information on receipt of formal psychiatric treatment was also obtained. Associated factors and predictors of "Any Mental Disorder" (AMD) were determined. Analysis was carried out using SPSS 20.0

Results Prevalence of psychological distress (GHQ score $>2$ ) was $63.8 \%$, psychosocial distress (DT score $>3$ ) (60.8\%), adjustment disorder (20.0\%), anxiety y disorder (18.5\%), major depression (15.4\%), delirium (6.9\%), psychosis (2.3\%), mania (0.8\%), 12-month alcohol use disorder (3.8\%), 12-month tobacco use disorder (0.8\%), 12-month opioid use disorder (26.9\%) and 12 month cannabis use disorder (0.8)\%. In all, $66.9 \%$ had AMD. The most common medical comorbidity was hypertension (36.2\%) and diabetes (23.1\%). Predictors of AMD were: Predictors of AMD were: duration of cancer treatment above 6 months $\mathrm{OR}=2.66,95 \% \mathrm{Cl}(1.17-6.05), \mathrm{DT}$ score $>3 \mathrm{OR}=2.78,95 \% \mathrm{Cl}(1.24-6.21)$ and the presence of any medical comorbidity $\mathrm{OR}=2.29,95 \% \mathrm{Cl}(1.02-5.14)$.

Conclusion Cancer is associated with significant psychiatric morbidity, necessitating a collaborative Consultation Liaison Psychiatric service in cancer care.

\section{Background}

Cancer is a leading cause of mortality worldwide, with about $70 \%$ of cancer-related mortality occurring in low- and middle-income countries[1]. It has been projected that cancer-related mortality will continue to rise to over 11 million by 2030 [1]. Nigeria is no exception to this, as data indicate that a total of 41,000 deaths from cancer in 2018, out of an estimated 166,000 cases recorded in the country [2]

The greatest increase in cancer morbidity and mortality will occur in low-and lower-middle-income countries because of epidemiological shift from communicable diseases to chronic non-communicable diseases, including cancer [3]. The increase in the incidence of cancer is driven by several factors such as population growth, greater detection and reporting, lifestyle risk factors including alcohol and drug use and by infection by oncogenic viruses, such as hepatitis B and C, human papillomavirus or Helicobacter pylori [4, 5].

Upon the diagnosis of cancer, a wide range of emotional distress develops along the cancer journey, ranging from mild psychological distress to diagnosable DSM V disorder [6-9]. Distress is particularly common in cancer trajectory and the International Federations of Psycho-Oncology Societies had endorsed distress as the "sixth vital sign" in cancer [10].

In terms of specific DSM V disorders, the prevalence of any 12 month mental disorder had been reported to be $39.4 \%$ in Germany [11], of which the prevalence of anxiety disorders was $15.8 \%$, mood disorders $12.5 \%$, somatoform disorders $9.5 \%$, nicotine dependence $7.3 \%$, alcohol abuse or dependence $1.1 \%$ and $3.7 \%$ for disorders due to general medical conditions. In a meta-analysis, the pooled prevalence of any mental disorder was 32\% [12], prevalence of mood disorders ranged from $30 \%$ to $40 \%$ [13] and depression $8 \%$ to $24 \%$ [14]. In another meta-analysis in China, the prevalence of depression was $54.9 \%$ and anxiety $49.7 \%$ [15]. In Japan, descriptive analysis of psychiatric referrals at two Japanese cancer hospitals indicated that $34 \%$ had adjustment disorder, $19 \%$ had sleep disorders, $18 \%$ anxiety, $14 \%$ major depression and $17 \%$ had delirium.

In Nigeria, South of Sahara, there is a serious dearth in the number of mental health specialists in all cadres, there is also a high unmet needs of individuals with mental disorders [16]. The situation is gloomier among patients with chronic, general medical conditions such as cancer because of poor detection rate of psychiatric morbidity by non-psychiatrist clinicians [17], partly due to ignorance, and also partly due to an overlap between somatic symptoms of common mental disorders [18], and side effects of cancer chemotherapy. Thus, it is important to gain insight into the prevalence of psychiatric morbidity in cancer, with its associated factors. This will form the template for the establishment of an effective consultation liaison psychiatric service in the department of oncology at the University College Hospital, Ibadan. This is expected to improve patents' outcome and quality of life.

It is in this context that the study was planned and the objective was to find the prevalence, correlates and predictors of 12-month "Any Mental Disorder "in cancer patients at the University College Hospital, Ibadan. We also examined the presence or absence of psychiatric treatment for those with cancer who have "Any Mental Disorder" (AMD). We defined AMD as any DSM IV disorder, including delirium and substance use disorder.

\section{Methods}

Study Design: This descriptive cross-sectional study.

Setting: This study was conducted at the Department of Radiation Oncology, University College Hospital, Ibadan, Nigeria, a 45-bed facility. The department was established in the year 1987 and has Telecobalt and HDR Co60 Brachytherapy machines with modern treatment planning system. The department is a referral centre for cancer patients that require radiotherapy both within the $\mathrm{UCH}$ and outside, and as far as some West African countries. From the registry of the department, about 300 new patients with cancer utilize the centre annually [19], thus our sampling frame was taken as 300 .

\section{Participants}

To be eligible for the study, participants were required to be adult patients, 18 years of age and above with the diagnosis of any cancer. They were consecutively recruited between June 2016 and March 2017. Excluded were patients who were too ill to follow up research protocols, those with a known psychiatric illness, and those patients not willing to give consent. Participants were selected by the use of multi-stage simple random sampling. At the first 
stage, all the 4 Oncology Departments in the University College Hospital, Ibadan were listed. During the second stage, the Radiation Oncology Department was selected by balloting.

At the Radiation Oncology Department, patients who met the eligibility criteria $(n=130)$ were consecutively recruited for the study (Figure I). The first subject that was interviewed was selected by simple random sampling and subsequent ones consecutively recruited until the minimum sample was met. An effort was made not to duplicate responses by using their hospital number and later allocating research number on a case by case basis.

\section{Variables}

\section{Dependent Variable/Outcome Variable}

The dependent/outcome variable was "Any Mental Disorder" (AMD) which was defined as any DSM IV disorder, including delirium and substance use disorder. Independent Variable

Independent variables were sociodemographic characteristics such as age, sex, employment status, marital status, religion, ethnicity as well as clinical characteristics such as stage of the cancer, duration of treatment, type of treatments received by the patient and presence or medical comorbidity. Other independent variables were presence of psychological distress (GHQ score $>2$ ) and presence of psychosocial distress, DT score $>3$ ).

\section{Confounding Variables}

The potential confounding variable was GHQ score $>2$ and this was adjusted for during multivariate analysis.

Predictors were variables that were significantly associated with AMD during multivariate analysis, using variables that were significantly associated with AMD during univariate analysis. These were duration of treatment of the cancer, presence of psychosocial distress (DT > 3), and presence of medical comorbidity.

\section{Data Sources}

\section{Sociodemographic and Clinical Questionnaire}

The sociodemographic questionnaire yielded information on age, sex, employment of the patient, marital status, religion, ethnicity, stage of the cancer, presence or medical comorbidity, type and number of treatments received by the patient,

\section{12-Item General Health Questionnaire (GHQ 12)}

The GHQ 12 is a screening instrument for psychiatric morbidity. Although it does not yield a diagnosis, positive scores are indicative of psychological distress. Each item is rated either 0 or 1 on the basis of the frequency with which the subject has experienced the symptom in the recent past, yielding a maximum score of 12. A score of 1 or above is suggestive of psychological distress; however, to increase specificity, a cutoff point of 2 was used, and score of 3 regarded as positive screen [20].

\section{Distress Thermometer}

The Distress Thermometer (DT) was developed as a simple tool to effectively screen for symptoms of distress. The instrument is a self-reported tool using a 0-to-10 rating scale. Additionally, the patient is prompted to identify sources of distress using a Problem List [21].

The cutoff point on the distress thermometer (DT) is 3, and those who score above 3 are classified as having psychosocial distress, which was adopted in the present study. Usually, patients who score a 4 or higher on the DT s more items from the NCCN Problem List [22]. Studies have shown that the DT is positively correlated with the Hamilton Anxiety and Depression Scale [23, 24] and the 12-Item General Health Questionnaire (GHQ 12) [25, 26].

\section{Delirium}

The Confusion Assessment Method (CAM) was used to establish the diagnosis of delirium. The CAM consists of nine questions which correlate with DSM IV criteria for delirium [27]. The questionnaire is administered in about 5 minutes following an initial observation of the patient during a cognitive screening test, the Mini-Mental State Examination (MMSE). The diagnosis of delirium made using a standard algorithm which is part of the CAM instrument. The CAM diagnostic algorithm is based on four cardinal features of delirium: 1) acute onset and fluctuating course, 2) inattention, 3) disorganized thinking, and 4) altered level of consciousness. A diagnosis of delirium, according to the CAM requires the presence of features 1, 2, and either 3 or 4 [28, 29]. The CAM when compared with clinician diagnoses using DSM IV criteria, has a sensitivity of $94-100 \%$ and a specificity of $90-95 \%$ [30].

\section{Mini-International Neuropsychiatric Interview (MINI)}

The Mini-International Neuropsychiatric Interview (M.I.N.I.) is a brief structured interview designed to make a diagnosis according to DSM-IV and ICD-10 criteria [31]. The instrument has been found to have similar psychometric properties in different parts of the world and different modules of the MINI have been used in the past in Nigerian studies [32-36]. The psychotic, major depressive disorder, bipolar, anxiety, and alcohol and substance modules of the MINI were used to determine the presence or absence of AMD. Adjustment disorder was diagnosed according to the DSM IV-TR criteria by the authors [37]. 


\section{Cancer Staging}

Cancer staging was performed by one of us (AA) an oncologist and was based on the TNM classification. [38]. According to the classification, Stage 0 is carcinoma in situ for most cancers. This implies the cancer is at a very early stage and has not spread. Example is cervical intraepithelial neoplasm (CIN), Stage I cancer (early stage cancer) means the cancer is small and is confined to one area. Stages $2 a, 2 b$ and 3 mean the cancer is larger and has infiltrated the surrounding tissues or lymph nodes, while stage 4 means the cancer has metastasized.

\section{Medical Comorbidity}

Patients were classified as having medical comorbidity by using the proforma used to elicit the presence of medical comorbidity in mental disorders [39]. The proforma included health conditions such as anemia, hypertension, ischemic heart disease, bronchial asthma, chronic dermatitis, diabetes mellitus, thyroid diseases, chronic pain disorder, chronic headache, peptic ulcer disease, liver disease, osteomyelitis, hemorrhoids, tuberculosis, HIV/AIDS, hepatitis schistosomiasis, dracontiasis and malaria. This was supplemented by self- reports of any current health condition with a written medical report by the treating physician.

\section{Treatment Receipt}

Treatment receipt was evaluated by asking a yes/no question. "Have you ever received treatment for a mental disorder either in a formal setting such as the hospital or from an informal setting such as the spiritualist in the course of this cancer journey"?

\section{Interviewers}

Interviewers were 4 psychiatric resident doctors who had previously received training in clinical research. They had been part of our clinical research time over the course of their training.

\section{Bias}

To minimize study bias, a pre-test was conducted before the commencement of the study among 15 patients attending the medical oncology unit of the study centre (not part of current study). This was to ascertain the feasibility, applicability, understandability and the application time of all the instruments of data collection in a busy clinical setting. During this period, it was observed that the research protocols suited the proposed sample and the administration time was about 25 minutes which was regarded as adequate.

Selection bias was removed by employing simple randomly sampling to select the participant. Regression analysis further minimized bias by removing the effects of confounding variables.

\section{Sample Size}

Given the population size as 300 , at $95 \%$ confidence interval, and a $5 \%$ margin of error, the minimum sample was calculated using sample size table by Research Advisors as 169 [40]. However, 39 participants were excluded from the study for various reasons, including severe illness, and deaths.

\section{Data Analysis}

Data analyses were by descriptive statistics and was carried out on 130 participants. There were no missing data. The GHQ-12 and the DT both have cutoff points. Thus, their association with AMD, the association between sociodemographic characteristics versus AMD, the association between medical comorbidity and AMD as well as the association between cancer stage and AMD were sought using Chi square test. This was because the preliminary Shapiro Wilk test of normality carried out before the final analysis shows that all the independent variables differ significantly from a normal distribution. In order to determine the possible effects of confounding variables, the predictors of AMD were determined using binary logistic regression analysis, using variables that were significantly associated with AMD during univariate analysis. We adjusted for GHQ because of collinearity with DT. All analyses were set at $95 \% \mathrm{Cl}$ and performed using SPSS 20.0 .

\section{Results}

At the Radiation Oncology Department, we approached 169 subjects for the study, however, 130 met the eligibility criteria, were all interviewed and finally completed the study, a response rate of $76.9 \%$. The subjects excluded from the study were because of severe illness, and death in the course of the survey (Figure I). There were no missing data.

\section{Descriptive Data}

Their mean age was 53.74 (13.99) years. The majority 105 (80.8\%) were females. Almost half 61 (46.9\%) had post- secondary education, 113 (86.9\%) were in employment, 90 (69.2\%) were married, 91 (70.0\%) were Muslims, and 91 (70.0\%) were of Yoruba Ethnicity. Overall, 49 (37.3\%) of all cancers were in stage 1, $37(28.5 \%)$ in stage $2 a, 23(17.7 \%)$ in stage 2 b, $20(15.4 \%)$ in stage 3 , and only 1 (0.8\%) in stage $4 /$ distant metastasis. Also, $83(63.8 \%)$ of respondents had any medical comorbidity, 68 (52.3\%) were on a single form of therapy, while the duration of the cancer was less than 6 months in $66(50.8 \%)$ of cases (Table 1$)$. 
Table 1

Demography of Patients Living with Cancer

\begin{tabular}{|c|c|c|}
\hline Demography & $\mathrm{n}$ & $\%$ \\
\hline \multicolumn{3}{|l|}{ Age } \\
\hline $1-30$ & 6 & 4.6 \\
\hline $31-40$ & 14 & 10.8 \\
\hline $41-50$ & 39 & 30.0 \\
\hline $51-60$ & 32 & 24.6 \\
\hline $61-70$ & 20 & 15.4 \\
\hline $71-90$ & 19 & 14.6 \\
\hline \multicolumn{3}{|l|}{ Gender } \\
\hline Male & 25 & 19.2 \\
\hline Female & 105 & 80.8 \\
\hline \multicolumn{3}{|l|}{ Education } \\
\hline None & 18 & 13.8 \\
\hline Elementary & 31 & 23.8 \\
\hline Secondary & 20 & 15.4 \\
\hline Post-Secondary & 61 & 46.9 \\
\hline \multicolumn{3}{|l|}{ Employment } \\
\hline Employed & 113 & 86.9 \\
\hline Unemployed & 17 & 13.1 \\
\hline \multicolumn{3}{|l|}{ Marital Status } \\
\hline Single & 40 & 30.8 \\
\hline Married & 90 & 69.2 \\
\hline \multicolumn{3}{|l|}{ Religion } \\
\hline Christianity & 39 & 30.0 \\
\hline Islam & 91 & 70.0 \\
\hline \multicolumn{3}{|l|}{ Ethnicity } \\
\hline Yoruba & 91 & 70.0 \\
\hline Igbo & 18 & 13.8 \\
\hline Hausa/Fulani & 2 & 1.5 \\
\hline Others & 19 & 14.6 \\
\hline \multicolumn{3}{|l|}{ Stage of Disease } \\
\hline Stage 1 & 49 & 37.7 \\
\hline Stage $2 a$ & 37 & 28.5 \\
\hline Stage $2 b$ & 23 & 17.7 \\
\hline Stage 3 & 20 & 15.4 \\
\hline Stage 4/Metastasis & 1 & 0.8 \\
\hline \multicolumn{3}{|c|}{ Duration of Treatment* } \\
\hline 1-6 Months & 66 & 50.8 \\
\hline$>6$ Months & 64 & 48.5 \\
\hline \multicolumn{3}{|l|}{ No of Treatment Type } \\
\hline Single & 68 & 52.3 \\
\hline$*$ Median $=6$ & & \\
\hline
\end{tabular}

Page 5/15 


\begin{tabular}{|lcc|}
\hline Demography & $\mathbf{n}$ & $\%$ \\
\hline Multiple & 62 & 47.7 \\
\hline Any Medical Comorbidity & & \\
Yes & 83 & 63.8 \\
\hline No & 47 & 36.2 \\
\hline *Median $=6$ & & \\
\hline
\end{tabular}

The most prevalent of all cancers in the sample was breast cancer $52(40.0 \%)$, followed by Cancer of the uterus cervical cancer 34 ( $26.2 \%)$ and by prostatic cancer 10 (7.7\%) (Table 2).

Table 2

Types of Cancer

\begin{tabular}{|lll|}
\hline Diagnosis & $\mathbf{n}$ & $\mathbf{\%}$ \\
\hline Breast & 52 & 40.0 \\
Cervix \& Uterus & 34 & 26.2 \\
\hline Prostrate & 10 & 7.7 \\
\hline Thyroid & 9 & 6.9 \\
\hline Colorectal & 9 & 6.9 \\
\hline ENT & 9 & 6.9 \\
\hline Musculoskeletal System & 3 & 2.3 \\
\hline Haematological & 2 & 1.5 \\
\hline Lungs & 2 & 1.5 \\
\hline Total & 130 & 100.0 \\
\hline
\end{tabular}

In terms of profile of mental health problems, 83 (63.8\%) scored high on GHQ (>2), 79 (60.8\%) had psychosocial distress (scored >3 on Distress Thermometer), 26 (20.0\%) had adjustment disorder, 24 (18.5\%) had anxiety disorder, 20 (15.4\%) had major depression, 9 (6.9\%) had delirium, 3 (2.3\%) had psychosis, 1 (0.8\%) had mania, 5 (3.8\%) met criteria for 12-month alcohol use disorder, 1 (0.8\%) had 12 month tobacco use disorder, 35 (26.9\%) had 12 month opioid use disorder and 1 (0.8) 12 month cannabis use disorder.

Outcome Data

In all, 87 (66.9\%) had "Any Mental Health Problem" (Table 3). 
Table 3

Profile of Mental Health Problems

\begin{tabular}{|lll|}
\hline Mental Health Problems & $\mathbf{n}$ & $\%$ \\
\hline Psychological Distress GHQ > & 83 & 63.8 \\
\hline Psychosocial Distress > 3 on DT & 79 & 60.8 \\
\hline Adjustment Disorder & 26 & 20.0 \\
\hline Anxiety & 24 & 18.5 \\
\hline Depression & 20 & 15.4 \\
\hline Delirium & 9 & 6.9 \\
\hline Psychosis & 3 & 2.3 \\
\hline Mania & 1 & 0.8 \\
\hline 12 Month Alcohol Use Disorder & 5 & 3.8 \\
\hline 12 Month Tobacco Use Disorder & 1 & 0.8 \\
\hline 12 Month Opioid Use Disorder & 35 & 26.9 \\
\hline 12 Month Cannabis Use Disorder & 1 & 0.8 \\
\hline 12-Month Any DSM IV Disorder & 87 & 66.9 \\
\hline Note: Multiple Diagnoses Reported & & \\
\hline
\end{tabular}

The results also show that the most common medical comorbidity was hypertension (36.2\%) and diabetes (23.1\%) (Figure I1). In all, 83 (63.8\%) respondents had any medical comorbidity (Not in Any Table).

\section{Main Results}

There was no significant sociodemographic correlate of AMD. The results also show that a significantly higher proportion of patients who had been on treatment for over 6 months had AMD compared with those who had received treatment for 1 to 6 months $(79.6 \%$ versus $54.5 \%) X^{2}=8.9, p=0.003$. Furthermore, the results show that a significantly higher proportion of respondents who with a DT scores $>3$ had AMD compared with those who had DT scores $<4(71.2 \%$ Versus $51.0 \%) X^{2}=9.6, p=0.002$. Finally, a significantly higher proportion of respondents who had any medical comorbidity also has AMD compared with those without any medical comorbidity $(73.5 \%$ versus $55.3 \%) X^{2}=4.5, p=0.03$ (Table 4$)$. 
Table 4

Sociodemographic and Clinical Correlates of Any Mental Disorder

\begin{tabular}{|c|c|c|c|c|c|c|}
\hline \multirow{2}{*}{$\begin{array}{l}\text { Demography } \\
\text { Age }\end{array}$} & \multicolumn{2}{|c|}{ Yes } & \multicolumn{2}{|l|}{ No } & \multirow[t]{2}{*}{$x^{2}$} & \multirow[t]{2}{*}{$\mathbf{P}$} \\
\hline & $\mathrm{n}$ & $\%$ & $\mathrm{n}$ & $\%$ & & \\
\hline $1-30$ & 6 & 100.0 & 0 & 0.0 & 5.3 & 0.4 \\
\hline $31-40$ & 11 & 78.6 & 5 & 21.4 & & \\
\hline $41-50$ & 23 & 59.0 & 10 & 41.0 & & \\
\hline $51-60$ & 20 & 62.5 & 14 & 37.5 & & \\
\hline$>60$ & 27 & 67.2 & 14 & 32.8 & & \\
\hline \multicolumn{7}{|l|}{ Gender } \\
\hline Male & 20 & 80.0 & 5 & 20.0 & 2.3 & 0.1 \\
\hline Female & 67 & 63.8 & 38 & 36.2 & & \\
\hline \multicolumn{7}{|l|}{ Education } \\
\hline None & 14 & 77.8 & 4 & 22.2 & 2.2 & 0.5 \\
\hline Elementary & 18 & 58.1 & 13 & 41.93 & & \\
\hline Secondary & 13 & 65.0 & 7 & 35.0 & & \\
\hline Post-Secondary & 42 & 68.9 & 19 & 31.1 & & \\
\hline \multicolumn{7}{|l|}{ Employment } \\
\hline Employed & 12 & 70.6 & 5 & 29.4 & 0.1 & 0.7 \\
\hline Unemployed & 75 & 66.4 & 38 & 33.6 & & \\
\hline \multicolumn{7}{|l|}{ Marital Status } \\
\hline Single & 23 & 57.5 & 17 & 42.5 & 2.3 & 0.1 \\
\hline Married & 66 & 71.1 & 26 & 28.9 & & \\
\hline \multicolumn{7}{|l|}{ Religion } \\
\hline Christianity & 27 & 69.2 & 12 & 30.8 & 0.1 & 0.7 \\
\hline Islam & 60 & 65.9 & 31 & 34.1 & & \\
\hline \multicolumn{7}{|l|}{ Ethnicity } \\
\hline Yoruba & 61 & 67.0 & 30 & 33.0 & 1.9 & 0.6 \\
\hline Igbo & 13 & 72.2 & 5 & 27.8 & & \\
\hline Hausa/Fulani & 2 & 100.0 & 0 & 0.0 & & \\
\hline Others & 11 & 42.1 & 8 & 42.1 & & \\
\hline \multicolumn{7}{|l|}{ Stage of Disease } \\
\hline Stage 1 & 25 & 51.0 & 24 & 49.0 & 9.4 & 0.05 \\
\hline Stage $2 a$ & 29 & 78.4 & 8 & 21.6 & & \\
\hline Stage $2 b$ & 17 & 73.9 & 6 & 26.1 & & \\
\hline Stage 3 & 15 & 75.0 & 5 & 25.0 & & \\
\hline Stage 4/Metastasis & 1 & 100.0 & 0 & 0.0 & & \\
\hline \multicolumn{7}{|c|}{ Duration of Treatment* } \\
\hline 1-6 Months & 36 & 54.5 & 30 & 45.5 & 8.9 & 0.003 \\
\hline$>6$ Months & 50 & 79.4 & 13 & 20.6 & & \\
\hline \multicolumn{7}{|l|}{ No of Treatment Type } \\
\hline Single & 44 & 64.7 & 24 & 35.3 & 0.3 & 0.5 \\
\hline \multicolumn{7}{|l|}{ DT $>3$} \\
\hline *Median 6 years & & & & & & \\
\hline
\end{tabular}




\begin{tabular}{|c|c|c|c|c|c|c|}
\hline Demography & Yes & & No & & $x^{2}$ & $\mathbf{P}$ \\
\hline Yes & 61 & 77.2 & 18 & 22.8 & 9.6 & 0.002 \\
\hline No & 26 & 51.0 & 25 & 49.0 & & \\
\hline Multiple & 43 & 69.4 & 19 & 30.6 & & \\
\hline \multicolumn{7}{|c|}{ Any Medical Comorbidity } \\
\hline Yes & 61 & 73.5 & 22 & 26.5 & 4.5 & 0.03 \\
\hline No & 26 & 55.3 & 21 & 44.7 & & \\
\hline
\end{tabular}

After adjusting for GHQ because of its collinearity with DT, predictors of AMD were: duration of cancer treatment above 6 months OR $=2.66,95 \% \mathrm{Cl}$ (1.176.05), DT score $>3 \mathrm{OR}=2.78,95 \% \mathrm{Cl}(1.24-6.21)$ and the presence of any medical comorbidity $\mathrm{OR}=2.29,95 \% \mathrm{Cl}(1.02-5.14)(\mathrm{Table} 5)$.

Table 5

Predictors of Any Mental Disorder (Prediction, 71.9\%)

\begin{tabular}{|lllll|}
\hline & OR & $95 \% \mathrm{Cl}$ & p \\
\hline Variables & & Lower & Upper \\
\hline Duration of Treatment* & & & & \\
\hline $1-6$ Months & 1 & & & \\
\hline$>6$ Months & 2.66 & 1.17 & 6.05 & $0.02^{\star *}$ \\
\hline DT >3 & & & & \\
\hline No & 1 & & & \\
\hline Yes & 2.78 & 1.24 & 6.21 & $0.013^{* *}$ \\
\hline Any Medical Comorbidity & & & & \\
\hline No & 1 & & & \\
\hline $\begin{array}{l}\text { Yes } \\
\text { Out of 4 Oncology Departments } \\
\text { Medical Oncology } \\
\text { Surgical Oncology } \\
\text { Haematological Oncology } \\
\text { Radiation Oncology }\end{array}$ & & & & \\
\hline \begin{tabular}{l} 
Fig: 1 Sample Selection Flow Chart \\
\hline
\end{tabular} & & & & \\
\hline
\end{tabular}

\section{Discussion}

In this study that aimed at determining the Prevalence, correlates and predictors of mental disorders in cancer patients at the University College Hospital, Ibadan, our results indicate that more than two-thirds of the sample had "Any Mental Disorder" of which less than a fifth had ever received treatment for AMD, with none from a formal setting. The results also show that the predictors of AMD were presence of psychosocial distress (DT score $>3$ ), long duration of cancer treatment and the presence of any medical comorbidity.

To the best of the authors' knowledge, this will be the first comprehensive evaluation of mental health problems and receipt of treatment for such at the University College Hospital, Ibadan. The biggest cancer treatment facility in Nigeria.

In this study, psychological distress was reported in $63.8 \%$ and psychosocial distress in $60.8 \%$. This is not unexpected, given that upon receiving the diagnosis of cancer, a wide range of emotional distress develops along the cancer journey, ranging from mild psychological distress to diagnosable DSM $V$ disorder [69]. The prevalence of psychological distress (GHQ score $>2$ ) and psychosocial distress (DT score $>3$ ) reported herein are much higher than those reported from previous studies from more developed countries. For example. Among a sample of Korean patients with cancer, the prevalence of high DT score was $28.8 \%$ [41], while the prevalence of high GHQ score from another study was $35.1 \%$, with varying rate from $43.4 \%$ for lung cancer to $29.6 \%$ for gynecological cancers [42]. The high prevalence of psychological and psychosocial distress in our sample could be adduced to several factors, including the lack of adequate cancer support system and crises intervention network that handle psychosocial problems among cancer patients leading to a high unmet needs [43]. The emotional responses may also be due to physical symptoms such as pain, nausea, lymphoedema, and other distressing symptoms of the disease and unwanted side effects of cancer treatment. The stigma due to the diagnosis is also another source of emotional distress to the patients [6].

Adjustment disorder was reported in $20 \%$ of all patients. This figure seems low compared to figures reported from other parts of the world (34\%)[44]. This wide variation may be due to differences in the time period of the interview. Our results generally corroborate the results from previous studies indicating that 
people with cancer are at an alarming risk of psychiatric morbidity notably adjustment disorder, delirium, depression, anxiety, or mixed anxiety and depression [8].

Any anxiety disorder was reported in $18.5 \%$ of patients. Studies have reported prevalence of anxiety disorder in cancer to range between $19.0 \%$ [45] to $32.2 \%$ [46]. We found the prevalence of major depression to be $15.4 \%$. Reported prevalence of major depression in cancer varied from $0-38 \%$. This wide variation was reported to be due to various definitions of depression, different ascertainment tools, differences in methodological approaches as well as differences in population studied [47]. Delirium was reported in $6.9 \%$ of patients, This is very close to the $6.5 \%$ reported in India [48]. The prevalence of delirium in cancer patients has a wide variation from $5-30 \%$ and is substantially higher in the terminal stage of illness, where figures as high as $80 \%$ may be reported [49, 50]. The low rate of delirium from our sample may be because the study was carried out in the Radiation Oncology department, where a high proportion of them are not on chemotherapy, but radiotherapy [51].

We found that $2.3 \%$ of the patients had psychosis. The association between schizophrenia and cancer had produced inconsistent results. While some studies have reported an increased rate of cancer [52], some showed no increase [53], and some others a reduction in the incidence of cancer [51]. These inconsistent observations could be adduced to failure to control for some confounding factors (such as environmental and familial/genetic factors) and also presence of psychosis may vary based on type of cancer [51].

We also found that $1(0.8 \%)$ of our sample had bipolar I disorder (mania). Although there is limited literature on mania in cancer patients, steroid induced mania in a cancer patient had been previously reported [54].

In the current study, we observed that 3.8\% had 12-month alcohol use disorder, 0.8 had 12-month nicotine use disorder, $26.9 \%$ had 12 -month opioid use disorder and $0.8 \%$ has 12 -month cannabis use disorder. Reports generally claim that the prevalence of substance use disorder is low in cancer populations. For example, some studies have reported a prevalence of $1.1 \%$ for alcohol use disorder in cancer patients in Germany [11]. In another study in the United States, only $3 \%$ of inpatient and outpatient patients with cancer in a Cancer Centre had substance use disorder [55]. However, studies have demonstrated that approximately $55 \%$ of patients with cancer and $40 \%$ of survivors experience chronic cancer-related pain [56], for which about $43 \%$ of them and $10 \%$ of survivors use opioids to manage chronic cancer pain [57]. This has implications for continued non-medical use of opioids [58].

This finding has implication for the management of addiction in palliative care. The goal of such efforts is not complete abstinence, but exerting enough control over illicit drug and alcohol use to allow palliative care interventions to decrease suffering [59]. The presence of substance use disorder and psychosis in cancer is also a potential contributory factor for excess mortality in people with cancer [60].

We also noted that hypertensive heart disease and diabetes were the most commonly reported medical comorbidity. Indeed, cancer and cardiovascular diseases share certain common risk factors such as smoking, unhealthy diet and obesity, physical inactivity, diabetes mellitus, and alcohol abuse [61]. On the other hand, increased access to the modern chemotherapeutic agents that prolong survival of patients with cancer has implications for the development or worsening of hypertension, particularly in patients treated with angiogenesis inhibitors [62].

Our univariate analysis also shows that presence of psychosocial distress, long duration of cancer and of course its treatment, and the presence of any medical comorbidity were all significantly associated with AMD. These variables also remained as predictors of AMD during multivariate analysis.

Our finding regarding the association between psychosocial distress and AMD finds support from previous studies indicating that the DT used in assessing psychosocial distress has a high sensitivity and specificity in detecting major depression and adjustment disorder in cancer patients [63]. Indeed, it has been reported that the DT has a strong discriminatory power relative to the PHQ-9 in establishing the diagnosis of depression [64]. Given that over a third of the current sample has depression or adjustment disorder, our findings suggest the need for screening for diagnosable DSM IV or DSM V disorder in cancer patients.

The association between long duration of cancer treatment and AMD may be understandable, given that cancer chemotherapy [65], radiotherapy [66], or surgical treatment of carcinomas such as breast cancer $[67,68]$, are associated with anxiety or depression, of which chemotherapy and radiotherapy are administered over a period of time. So also, is the possibility of developing delirium from prolonged exposure to cancer treatment and possible adverse effects of drug/drug interaction [69].

Also, our observation that the presence of any medical comorbidity was associated with AMD is supported by previous studies [70, 71]. Unfortunately, the presence of medical comorbidity in cancer adds to the disease burden because of the difficulty in navigating different medical specialty treatment on one-part, independent burden posed by the medical condition, and the risk of drug/drug interaction on the other part.

The current study therefore, has implications for the integration of comprehensive consultation liaison psychiatric service into cancer care. The finding that $66.9 \%$ of the sample had AMD for which none is receiving any formal mental health care is a justification for this. Unless AMD is routinely screened for, this population of cancer patients may remain undetected, contributing to increased morbidity and mortality in cancer. Our findings call for increased and prompt access to cancer care in Nigeria. The development of the 2-item extremely brief and simple psychosis screening tool [72], and the 2 -item patients' health questionnaire that screens for depression [73] could increase the detection of severe mental disorders at the port of entry in the cancer journey. So also, there is the need for routine toxicological screen notably for opioids, because of its likelihood to be used out of prescription for cancer-related pain.

\section{Study Strength And Limitations}

The major strength of the current study is based on the fact that our sample of patients consists of patients with different types of cancer and also in different stages, nonetheless, the study has a number of potential limitations. First is that our sample was drawn from patients attending the department of radiation

Page $10 / 15$ 
oncology. The study was also limited by small sample size and prone to selection bias because the sample was recruited from one of oncology departments in the study site. However, our results should serve as a template for the establishment of an integrated intervention program for the concerned group and also be generalizable to any oncology unit in Nigeria, moreover patients with all types of cancer were sampled.

\section{Conclusion}

A significant proportion of patients with cancer has diagnosable DSM IV or DSM V disorder for which none of them had sought any formal mental health care for. Thus, there is the need for the screening of any DSM IV or DSM V disorder at the port of entry into the cancer journey.

\section{Abbreviations}

AMD

Any Mental Disorder

DT

Distress Thermometer

GHQ-12

12-Item General Health Questionnaire

HADS

Hospital Anxiety and Depression Scale

MINI

Mini International Neuropsychiatric Interview

CAM

Confusion Assessment Method

C.I.

Confidence Intervals

DSM-IV

Diagnostic Statistical Manual of Mental Disorders, 4th Edition

DSM-V

Diagnostic Statistical Manual of Mental Disorders, 5th Edition

OR

Odds ratios

$\mathrm{Cl}$

Confidence Intervals

\section{Declarations}

\section{Ethical Approval and Consent to Participate}

Ethical approval was obtained from the Joint UCH/UI Ethical Review Board and the study was carried in accordance with the Declaration of Helsinki regarding research work involving human beings. Written informed consent was also obtained from either the patient or the principal caregiver and all data were fully anonymized. All participants were 18 years or older, therefore, there was np need to obtain consent from the parent or guardian of any child under 16 years.

\section{Consent for Publications}

Not Applicable

\section{Availability of data and materials}

The data sets used during the current study are available from the corresponding author on reasonable request.

Competing Interest: Nil

Source of Funding: No Specific Funding

\section{Authors' contributions}

VL was involved in study design, data analysis and manuscript writing, SF was involved in study design and data collection, TL was involved in manuscript writing and final editing, MA was involved in data collection and final manuscript review, while AA was involved in final manuscript review. All authors agree to all the contents of the manuscript.

\section{Acknowledgements}


We acknowledge all the participants, the resident doctors at the Departments of Psychiatry and Radiation Oncology respectively as well as the nurses. We also acknowledge all the secretarial staff who assisted during the course of data collection, collation and publication.

\section{References}

1. Ferlay J, Shin HR, Bray F, Forman D, Mathers C, Parkin DM: Estimates of worldwide burden of cancer in 2008: GLOBOCAN 2008. International journal of cancer Journal international du cancer 2010, 127(12):2893-2917.

2. Nigeria records $\mathbf{4 1 , 0 0 0}$ cancer-related deaths in 2018 [http://www.xinhuanet.com/english/2019-02/05/c_137799542.htm]

3. Global Burden of Disease Liver Cancer Collaboration: The Burden of Primary Liver Cancer and Underlying Etiologies From 1990 to 2015 at the Global, Regional, and National Level: Results From the Global Burden of Disease Study 2015. JAMA Oncology 2017, 3(12):1683-1691.

4. Kanavos P: The rising burden of cancer in the developing world. Annals of Oncology 2006, 17(suppl_8):viii15-viii23.

5. Walker ZJ, Jones MP, Ravindran AV: Psychiatric disorders among people with cancer in low- and lower-middle-income countries: study protocol for a systematic review and meta-analysis. 2017, 7(8):e017043.

6. Chaturvedi SK: Psychiatric oncology: Cancer in mind. Indian journal of psychiatry 2012, 54(2):111-118.

7. Tada Y, Matsubara M, Kawada S, Ishida M, Wada M, Wada T, Onishi H: Psychiatric disorders in cancer patients at a university hospital in Japan: descriptive analysis of 765 psychiatric referrals. Japanese journal of clinical oncology 2012, 42(3):183-188.

8. Lang-Rollin I, Berberich G: Psycho-oncology. Dialogues in clinical neuroscience 2018, 20(1):13-22.

9. Cancer Treatment Center of America: The psychiatrist: The doctor you didn't expect to need on your cancer journey. In.; 2017.

10. Bultz BD, Travado L, Jacobsen PB, Turner J, Borras JM, Ullrich AWH: 2014 President's plenary international psycho-oncology society: moving toward cancer care for the whole patient. 2015, 24(12):1587-1593.

11. Kuhnt S, Brähler E, Faller H, Härter M, Keller M, Schulz H, Wegscheider K, Weis J, Boehncke A, Hund B et al: Twelve-Month and Lifetime Prevalence of Mental Disorders in Cancer Patients. Psychotherapy and psychosomatics 2016, 85(5):289-296.

12. Singer S, Das-Munshi J, Brahler E: Prevalence of mental health conditions in cancer patients in acute care-a meta-analysis. Annals of oncology : official journal of the European Society for Medical Oncology / ESMO 2010, 21(5):925-930.

13. Mitchell AJ, Chan M, Bhatti H, Halton M, Grassi L, Johansen C, Meader N: Prevalence of depression, anxiety, and adjustment disorder in oncological, haematological, and palliative-care settings: a meta-analysis of 94 interview-based studies. The Lancet Oncology 2011, 12(2):160-174.

14. Krebber AM, Buffart LM, Kleijn G, Riepma IC, de Bree R, Leemans CR, Becker A, Brug J, van Straten A, Cuijpers P et al: Prevalence of depression in cancer patients: a meta-analysis of diagnostic interviews and self-report instruments. Psychooncology 2014, 23(2):121-130.

15. Yang Y-L, Liu L, Wang Y, Wu H, Yang X-S, Wang J-N, Wang L: The prevalence of depression and anxiety among Chinese adults with cancer: a systematic review and meta-analysis. BMC Cancer 2013, 13(1):393.

16. Gureje O, Lasebikan V: Use of mental health services in a developing country. Results from the Nigerian survey of mental health and well-being. Soc Psychiatry Psychiatr Epidemiol 2006, 41(1):44-49.

17. Enkhe Badamgarav, M.D., M.P.H. „, Scott R. Weingarten, M.D., M.P.H. „ James M. Henning, M.S. „, Kevin Knight, M.D., M.P.H. „Vic Hasselblad, Ph.D. „” Anacleto Gano J, , M.P.H. , and, Joshua J. Ofman, M.D., M.S.H.S.: Effectiveness of Disease Management Programs in Depression: A Systematic Review. 2003, 160(12):2080-2090.

18. Scicchitano J, Lovell P, Pearce R, Marley J, Pilowsky I: Illness behavior and somatization in general practice. Journal of Psychosomatic Research 1996, 41(3):247-254

19. Dairo MD, Adamu DB, Onimode YA, Ntekim A, Ayeni O: Characteristics and Determinants of Patients Discontinuation of Breast Cancer Follow-Up Care at the Radiation Oncology Department, University College Hospital, Ibadan, Nigeria. Int J Breast Cancer 2018, 2018:1597964-1597964.

20. Goldberg DP, Gater R, Sartorius N, Ustun TB, Piccinelli M, Gureje O, Rutter C: The validity of two versions of the GHQ in the WHO study of mental illness in general health care. Psychol Med 1997, 27(1):191-197.

21. Ownby KK: Use of the Distress Thermometer in Clinical Practice. J Adv Pract Oncol 2019, 10(2):175-179.

22. VanHoose L, Black LL, Doty K, Sabata D, Twumasi-Ankrah P, Taylor S, Johnson R: An analysis of the distress thermometer problem list and distress in patients with cancer. Supportive care in cancer : official journal of the Multinational Association of Supportive Care in Cancer 2015, 23(5):1225-1232.

23. Itani Y, Arakawa A, Tsubamoto H, Ito K, Nishikawa R, Inoue K, Yamamoto S, Miyagi Y, Hori K, Furukawa N: Validation of the distress and impact thermometer and the changes of mood during the first 6 months of treatment in gynecological cancer patients: a Kansai Clinical Oncology Group (KCOG)G1103 prospective study. Archives of gynecology and obstetrics 2016, 294(6):1273-1281

24. Alosaimi FD, Abdel-Aziz N, Alsaleh K, AlSheikh R, AlSheikh R, Abdel-Warith A: Validity and feasibility of the Arabic version of distress thermometer for Saudi cancer patients. PloS one 2018, 13(11):e0207364-e0207364.

25. Gunnarsdottir S, Thorvaldsdottir GH, Fridriksdottir N, Bjarnason B, Sigurdsson F, Skulason B, Smari J: The psychometric properties of the Icelandic version of the distress thermometer and problem list. Psychooncology 2012, 21(7):730-736.

26. Gessler S, Low J, Daniells E, Williams R, Brough V, Tookman A, Jones L: Screening for distress in cancer patients: is the distress thermometer a valid measure in the UK and does it measure change over time? A prospective validation study. Psychooncology 2008, 17(6):538-547.

27. American Psychiatric Association: Diagnostic and Statistical Manual of Mental Disorders. In. Edited by Association AP, 4th edn. Washington DC; 1994.

28. Inouye SK, van Dyck CH, Alessi CA, Balkin S, Siegal AP, Horwitz Rl: Clarifying confusion: the confusion assessment method. A new method for detection of delirium. Ann Intern Med 1990, 113(12):941-948. 
29. Wei LA, Fearing MA, Sternberg EJ, Inouye SK: The Confusion Assessment Method: a systematic review of current usage. Journal of the American Geriatrics Society 2008, 56(5):823-830.

30. Waszynski CM: Confusion Assessment Method (CAM). Medsurg nursing : official journal of the Academy of Medical-Surgical Nurses 2004, 13(4):269-270.

31. Sheehan DV, Lecrubier Y, Sheehan KH, Janavs J, Weiller E, Keskiner A, Schinka J, Knapp E, Sheehan MF, Dunbar GC: The validity of the Mini International Neuropsychiatric Interview (MINI) according to the SCID-P and its reliability. Eur Psychiatry 1997, 12(5):232-241.

32. Adewuya AO: Prevalence of major depressive disorder in Nigerian college students with alcohol-related problems. Gen Hosp Psychiatry 2006, 28(2):169173.

33. Adewuya AO, Afolabi MO, Ola BA, Ogundele OA, Ajibare AO, Oladipo BF, Fakande I: Relationship between depression and quality of life in persons with HIV infection in Nigeria. Int $J$ Psychiatry Med 2008, 38(1):43-51.

34. Adewuya AO, Ola BA, Aloba 00, Mapayi BM: Anxiety disorders among Nigerian women in late pregnancy: a controlled study. Arch Womens Ment Health 2006, 9(6):325-328.

35. Lasebikan VO, Ige OM: Suicidality in Tuberculosis Patients and their Non-Tuberculosis Family Contacts in Nigeria. Mental Health in Family Medicine 2016, 12:100-109

36. Lasebikan V, Ige OJMHFM: Suicidality in tuberculosis patients and their NonTuberculosis family contacts in Nigeria. 2016, 12:100-109.

37. American Psychiatric Association: Diagnostic Statistical Manual 5th Edition. In., V edn: American Psychiatric Association; 2014.

38. Cancer Staging [https://www.cancer.org/treatment/understanding-your-diagnosis/staging.html]

39. Lasebikan VO, Azegbeobor J: Medical Co-morbidities Among Patients with Severe Mental Illnesses in a Community Health Facility in Nigeria. Community Ment Health J 2017, 53(6):736-746.

40. [http://research-advisors.com/ ]

41. Kim SJ, Rha SY, Song SK, Namkoong K, Chung HC, Yoon SH, Kim GM, Kim KR: Prevalence and associated factors of psychological distress among Korean cancer patients. Gen Hosp Psychiatry 2011, 33(3):246-252.

42. Zabora J, BrintzenhofeSzoc K, Curbow B, Hooker C, Piantadosi S: The prevalence of psychological distress by cancer site. Psychooncology 2001, 10(1):19-28.

43. Fatiregun O, Sowunmi AC, Habeebu M, Okediji P, Alabi A, Fatiregun O, Adeniji A, Awofeso O, Adegboyega B: Prevalence and Correlates of Unmet Supportive Needs of Nigerian Patients With Cancer. J Glob Oncol 2019, 5:1-9.

44. Akechi T, Nakano T, Okamura H, Ueda S, Akizuki N, Nakanishi T, Yoshikawa E, Matsuki H, Hirabayashi E, Uchitomi Y: Psychiatric Disorders in Cancer Patients: Descriptive Analysis of 1721 Psychiatric Referrals at Two Japanese Cancer Center Hospitals. Japanese journal of clinical oncology 2001, 31(5):188-194.

45. Linden W, Vodermaier A, Mackenzie R, Greig D: Anxiety and depression after cancer diagnosis: prevalence rates by cancer type, gender, and age. $J$ Affect Disord 2012, 141(2-3):343-351.

46. Tsaras K, Papathanasiou IV, Mitsi D, Veneti A, Kelesi M, Zyga S, Fradelos EC: Assessment of Depression and Anxiety in Breast Cancer Patients: Prevalence and Associated Factors. Asian Pacific journal of cancer prevention : APJCP 2018, 19(6):1661-1669.

47. Massie MJ: Prevalence of depression in patients with cancer. Journal of the National Cancer Institute Monographs 2004(32):57-71.

48. Gopalan MR, Karunakaran V, Prabhakaran A, Jayakumar KL: Prevalence of psychiatric morbidity among cancer patients - hospital-based, cross-sectional survey. Indian journal of psychiatry 2016, 58(3):275-280.

49. Breitbart W, Alici Y: Evidence-Based Treatment of Delirium in Patients With Cancer. Journal of Clinical Oncology 2012, 30(11):1206-1214.

50. Farriols Danés C, Landa Teran CP, Ruiz Ripoll Al, Planas Domingo J: Prevalencia del delirium en pacientes con enfermedad oncológica avanzada ingresados en una unidad de cuidados paliativos. Medicina Paliativa 2016, 23(4):165-171.

51. Hodgson R, Wildgust HJ, Bushe CJ: Cancer and schizophrenia: is there a paradox? Journal of psychopharmacology (Oxford, England) 2010, 24(4 Suppl):51-60.

52. Lichtermann D, Ekelund J, Pukkala E, Tanskanen A, Lonnqvist J: Incidence of cancer among persons with schizophrenia and their relatives. Arch Gen Psychiatry 2001, 58(6):573-578.

53. Catts VS, Catts SV, O'Toole BI, Frost AD: Cancer incidence in patients with schizophrenia and their first-degree relatives - a meta-analysis. Acta Psychiatr Scand 2008, 117(5):323-336.

54. Warren KN, Katakam J, Espiridion ED: Acute-onset Mania in a Patient with Non-small Cell Lung Cancer. Cureus 2019, 11 (8):e5436.

55. Prevalence of Substance Abuse Disorders in Cancer Patients [https://www.cancernetwork.com/review-article/prevalence-substance-abuse-disorderscancer-patients/page/0/2]

56. van den Beuken-van Everdingen M, de Rijke J, Kessels A, Schouten H, van Kleef M, Patijn J: Prevalence of pain in patients with cancer: a systematic review of the past 40 years. Annals of Oncology 2007, 18(9):1437-1449.

57. Patient Quality of Life Coalition: Key Findings Summary: Opioid Access Research Project. [https://www.fightcancer.org/sites/default/files/ACS\%20CAN\%20PQLC\%200pioid\%20Research\%20Project\%20Key\%20Findings\%20Summary\%20Memo\%

58. Lasebikan VO, ljomanta I: Non-medical prescription opioid use and opioid use disorder in the military population in Nigeria. Journal of Substance Use 2019, 24(2):192-198.

59. Passik SD, Theobald DE: Managing Addiction in Advanced Cancer Patients: Why Bother? Journal of pain and symptom management 2000, 19(3):229234. 
60. Manderbacka K, Arffman M, Suvisaari J, Ahlgren-Rimpilainen A, Lumme S, Keskimaki I, Pukkala E: Effect of stage, comorbidities and treatment on survival among cancer patients with or without mental illness. Br J Psychiatry 2017, 211(5):304-309.

61. Souza VBd, Silva EN, Ribeiro ML, Martins WdA: Hypertension in patients with cancer. Arq Bras Cardiol 2015, 104(3):246-252.

62. Scartozzi M, Galizia E, Chiorrini S, Giampieri R, Berardi R, Pierantoni C, Cascinu S: Arterial hypertension correlates with clinical outcome in colorectal cancer patients treated with first-line bevacizumab. Annals of oncology : official journal of the European Society for Medical Oncology / ESMO 2009, 20(2):227-230.

63. Akizuki N, Yamawaki S, Akechi T, Nakano T, Uchitomi Y: Development of an Impact Thermometer for use in combination with the Distress Thermometer as a brief screening tool for adjustment disorders and/or major depression in cancer patients. Journal of pain and symptom management 2005, 29(1):9199.

64. Hegel MT, Collins ED, Kearing S, Gillock KL, Moore CP, Ahles TA: Sensitivity and specificity of the Distress Thermometer for depression in newly diagnosed breast cancer patients. Psycho-oncology 2008, 17(6):556-560.

65. Pandey M, Sarita GP, Devi N, Thomas BC, Hussain BM, Krishnan R: Distress, anxiety, and depression in cancer patients undergoing chemotherapy. World journal of surgical oncology 2006, 4:68.

66. Schmale AH, Morrow GR, Davis A, Illies E, McNally J, Wright G, Craytor JK: Pretreatment behavioral profiles associated with subsequent psychosocial adjustment in radiation therapy patients: a prospective study. Int J Psychiatry Med 1982, 12(3):187-195.

67. Morris T, Greer HS, White P: Psychological and social adjustment to mastectomy: a two-year follow-up study. Cancer 1977, 40(5):2381-2387.

68. Maguire GP, Lee EG, Bevington DJ, Kuchemann CS, Crabtree RJ, Cornell CE: Psychiatric problems in the first year after mastectomy. Br Med J 1978, 1(6118):963-965.

69. Matsuoka H, Yoshiuchi K, Koyama A, Otsuka M, Nakagawa K: Chemotherapeutic drugs that penetrate the blood-brain barrier affect the development of hyperactive delirium in cancer patients. Palliative and Supportive Care 2015, 13(4):859-864.

70. Anuk D, Özkan M, Kizir A, Özkan S: The characteristics and risk factors for common psychiatric disorders in patients with cancer seeking help for mental health. BMC Psychiatry 2019, 19(1):269.

71. Ng HS, Roder D, Koczwara B, Vitry A: Comorbidity, physical and mental health among cancer patients and survivors: An Australian population-based study. 2018, 14(2):e181-e192.

72. Phalen PL, Rouhakhtar PR, Millman ZB, Thompson E, DeVylder J, Mittal V, Carter E, Reeves G, Schiffman J: Validity of a two-item screen for early psychosis. Psychiatry research 2018, 270:861-868.

73. Kroenke K, Spitzer RL, Williams JB: The Patient Health Questionnaire-2: validity of a two-item depression screener. Med Care 2003, 41(11):1284-1292.

\section{Figures}
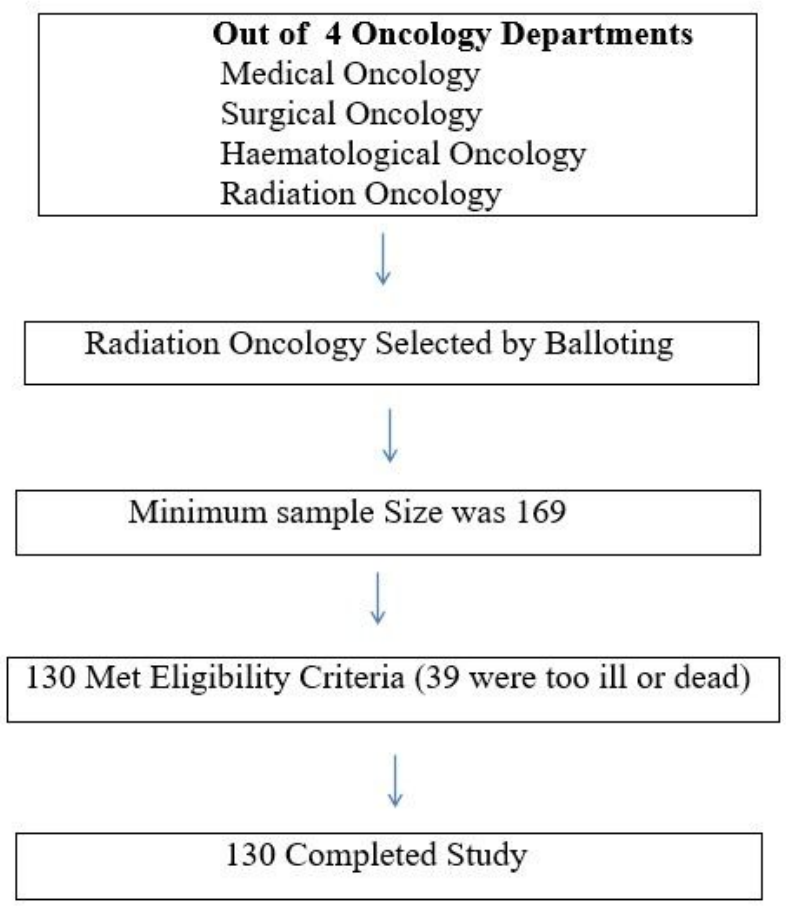

Figure 1

Sample Selection Flow Chart 


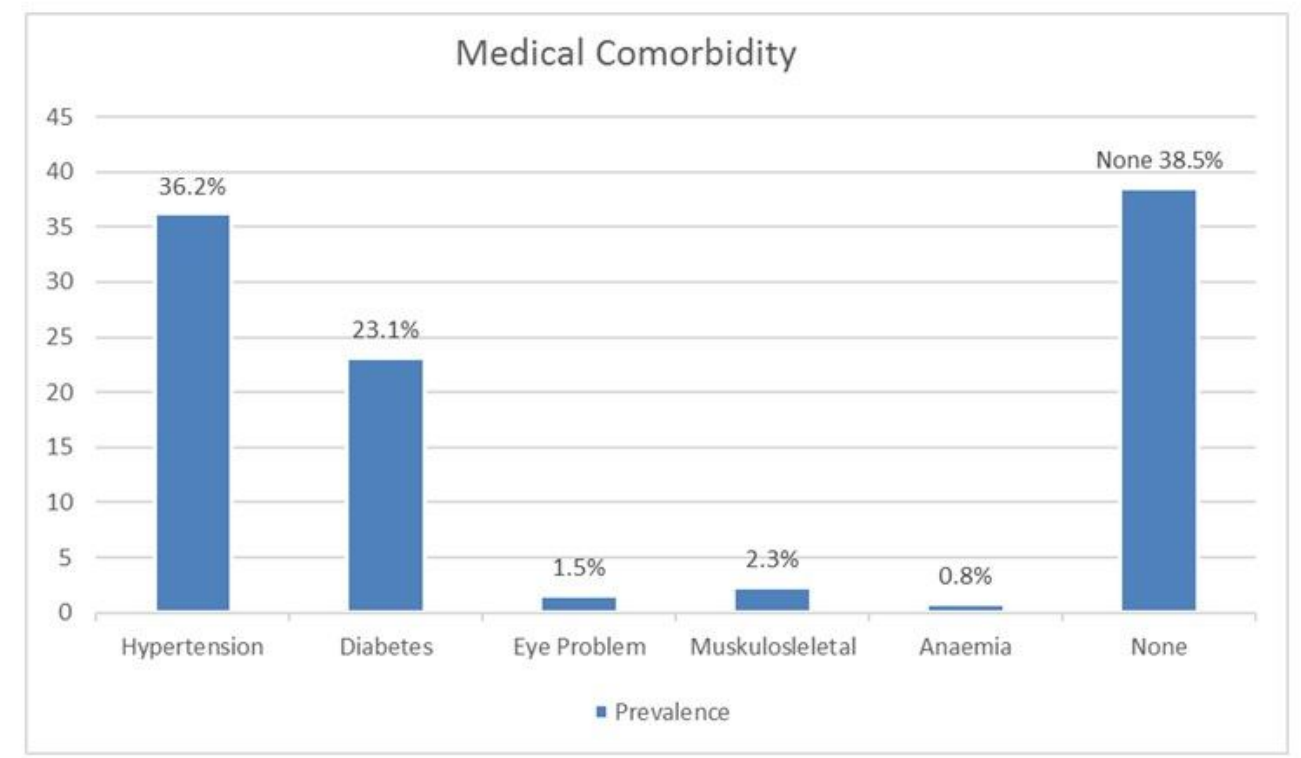

\section{Figure 2}

Profile of Medical Comorbidities

\section{Supplementary Files}

This is a list of supplementary files associated with this preprint. Click to download.

- STROBEchecklistcrosssectional.doc 